\title{
Cancer occurrence in a cohort of patients treated with cimetidine
}

\author{
H MøLLER, K LINDVIG, R KLEFTER, J MOSBECH, \\ AND O MØLLER JENSEN \\ From the Danish Cancer Society, Danish Cancer Registry, Copenhagen, Denmark and the Department of \\ Medicine, Copenhagen County Hospital, St Elisabeth's Hospital, Copenhagen, Denmark
}

SUMMARY The possible carcinogenic effects of antisecretory agents used in the treatment of gastric and duodenal ulcer were investigated in a population based cohort study of 16739 patients who were prescribed the $\mathrm{H}_{2}$-antagonist cimetidine between 1977 and 1981. An excess risk for gastric cancer was observed, with a relative risk of about 10 in the first year after beginning use of the drug, which decreased thereafter. A similar pattern was seen for cancers of the colon, pancreas and gall bladder, and for non-Hodgkin's lymphoma. These increased risks probably represent cases in which a malignancy was misdiagnosed as a gastric ulcer. The excess risk for gastric cancer was unaffected by the method of diagnosis, the risk in those who had undergone an endoscopy being similar to those who had been diagnosed by an $x$-ray examination. A relative risk of 1.5-2.0 was observed for cancer of the respiratory organs, with no effect of latency, indicating that there are common risk factors for peptic ulcer and for lung cancer. Although the observed increases in cancer risk in persons receiving cimetidine is probably caused by factors other than a carcinogenic action of the drug itself, this possibility cannot be ruled out because of the short period of follow up.

Since the introduction of $\mathrm{H}_{2}$-receptor antagonists for the treatment of gastric and duodenal ulcers, concern has been raised that their use may be accompanied by a number of side effects. Case reports have been published in which one such drug, cimetidine, was given to patients with a misdiagnosed gastric cancer, thus delaying diagnosis and perhaps reducing the possibility of radical surgical treatment.$^{1-3}$ Furthermore, the lowered gastric acidity that occurs after use of these antisecretory drugs may enhance carcinogenesis. The risk for gastric cancer has been shown to increase in patients with other conditions that result in low gastric acidity, such as persons with pernicious anaemia,${ }^{45}$ and several large, longterm follow up studies of patients who had had a partial gastrectomy have shown an increased risk for gastric cancer after a latent period of about 20 years..$^{-4}$ Gastric hypoacidity favours bacterially mediated reduction of nitrate to nitrite and formation of N-nitroso compounds. ${ }^{10}$ To what extend this occurs in to longterm users of

Address for correspondence: Dr H Møller. Danish Cancer Society. Danish Cancer Registry, Rosenvaengets Hovedvej 35. Box 839. DK-2100. Copenhagen, Denmark.

Accepted for publication 21 March 1989. cimetidine is not known, "12 but increased concentrations of $\mathrm{N}$-nitroso compounds have been shown in the gastric juice of cimetidine users ${ }^{13}$ and in those with pernicious anaemia and those who have undergone a partial gastrectomy. ${ }^{1+}$

We describe the occurrence of cancer in a large cohort of patients who had used cimetidine during the first few years after its introduction in Denmark in September 1977. The dose of cimetidine used in this period was $200 \mathrm{mg}$ five times per day. Since follow up of the cohort was possible over an average of 4.5 years, with a maximum of eight years, only short term epidemiological effects could be evaluated.

\section{Methods}

SUBJECTS

This study is based on the list of applications for reimbursement of the cost of cimetidine maintained at the Danish National Board of Health. The material was described in detail by Schmidt et al. ${ }^{15}$ Between September 1977 and introduction of reimbursement by the National Health Service insurance scheme in July 1981, cimetidine users could 
Table 1 Numbers of persons, person-years, and cases of cancer observed during follow up of patients receiving cimetidine, by diagnosis and by method of diagnosis

\begin{tabular}{|c|c|c|c|c|c|}
\hline $\begin{array}{l}\text { Diseasel } \\
\text { diagnostic } \\
\text { method }\end{array}$ & Sex & $\begin{array}{l}\text { Persons } \\
\text { (n) }\end{array}$ & $\begin{array}{l}\text { Person- } \\
\text { years }\end{array}$ & $\begin{array}{l}\text { Mean } \\
\text { follow up } \\
\text { (yr) }\end{array}$ & $\begin{array}{l}\text { Observed } \\
\text { cancers } \\
\text { (n) }\end{array}$ \\
\hline \multirow[t]{2}{*}{ Duodenal ulcer } & Males & 6740 & 31023 & $4 \cdot 6$ & 344 \\
\hline & Females & 3093 & 14295 & $4 \cdot 6$ & 159 \\
\hline \multirow[t]{2}{*}{ Gastric ulcer } & Males & 2795 & 12076 & $4 \cdot 3$ & 2() 4 \\
\hline & Females & 2292 & 9901 & $4 \cdot 3$ & 168 \\
\hline \multirow[t]{2}{*}{ Other diagnosis } & Males & 1159 & 5172 & 4.5 & 65 \\
\hline & Females & 660 & 28.57 & $4 \cdot 3$ & 32 \\
\hline \multirow[t]{2}{*}{ Endoscopy } & Males & 3284 & 14120 & $4 \cdot 3$ & 224 \\
\hline & Females & 2074 & 8981 & $4 \cdot 3$ & 129 \\
\hline \multirow[t]{2}{*}{$X$-ray } & Males & 5748 & 26531 & $4 \cdot 6$ & 281 \\
\hline & Females & 2991 & 13664 & $4 \cdot 6$ & 168 \\
\hline \multirow[t]{2}{*}{ Not stated } & Males & 1662 & 7620 & $4 \cdot 6$ & 108 \\
\hline & Females & 980 & 4408 & 4.5 & 62 \\
\hline \multirow[t]{3}{*}{ Total } & Males & 10694 & 48271 & 4.5 & 613 \\
\hline & Females & 6045 & 270.53 & 4.5 & 359 \\
\hline & Both & 16739 & 75.324 & 4.5 & 972 \\
\hline
\end{tabular}

apply for reimbursement of part of the cost of the drug. Because cimetidine treatment is expensive, it is assumed that most people who used it during that period applied for reimbursement.

The following information was available for 19154 applications: personal identification number, date of birth, month and year of application, the diagnosis of the disease for which the drug was being prescribed, and the diagnostic basis. Altogether, 163 duplicate registrations and 35 persons with insufficient identifiers were eliminated, as well as 1358 persons who were given the drug for a diagnosis other than duodenal ulcer, gastric ulcer, gastritis/duodenitis, or coexisting duodenal and gastric ulcer, or for whom the diagnostic procedure had been an operation. A further 859 persons with a malignancy diagnosed during the month of application for reimbursement or earlier were also deleted. This left 16739 persons for study. These were followed up for death and emigration by computerised record linkage with the Danish National Population Register. All cases of cancer in Denmark have been registered with the nationwide Danish Cancer Registry since 1943, ${ }^{\text {th }}$ and follow up for cancer morbidity was undertaken by computerised record linkage.

Person-years at risk were computed from the date of application until date of cancer diagnosis, death, emigration, or 31 December 1984, whichever occurred first. Computations were carried out by means of a FORTRAN program. ${ }^{17}$ Number of persons, person-years of follow up and observed number of cases of cancer during follow up and tabulated by diagnosis and diagnostic mothod in Table 1. The average length of follow up was $4 \cdot 5$ years, and a total of 972 cases of cancer were diagnosed. The expected numbers of cancer cases were calculated by multiplying national age (five year intervals), sex, and calendar period (five year intervals) specific incidence rates by the corresponding number of personyears. Relative risks were derived by dividing the observed number of cancer cases by the expected number. One sided $p$ values were calculated under the assumption that the observed number of cases followed a Poisson distribution to test whether the relative risks exceeded unity.

\section{Results}

Tables 2 and 3 give the relative risks for cancer in men and women, respectively. The relative risk for cancer at all sites was 1.9 in men and 1.7 in women during the first year after beginning cimetidine treatment. This risk decreased with time in both sexes. The risk for developing cancer of the digestive organs immediately after starting to use the drug was more than three times higher than that in the general population but declined gradually with time. This increased risk is accounted for mainly by the very high relative risks (roughly 10-fold) for cancers of the stomach and of the small intestine during the first year after start of cimetidine use in men and during the first three years in women. Ninety one per cent of the gastric cancers which occurred in the cohort were histologically verified. Increased risk of colon and pancreatic cancers were also seen immediately after starting to use cimetidine, which decreased long term.

In both men and women, excess risks for malignancies of the lymphatic and haematopoietic system were seen during the first year of follow up only. The risk for developing cancer of the respiratory organs was increased, with relative risks of about 1.5 throughout the period of follow up. Relative risks for cancer of the urinary system were increased significantly one to three years after start of cimetidine use in men and three to five years in women. A significantly raised relative risk of 1.8 was seen for cancer of the genital organs in men only in the first year of follow up.

The occurrence of gastric cancer in the cohort is further analysed in Table 4 . The excess risk is largely confined to men and women with a diagnosis of gastric ulcer, who had a 20-fold increase in the first year of follow up, which declined gradually to a relative risk of 4.8 five or more years after start of cimetidine use. The relative risk after cimetidine treatment for duodenal ulcer was increased only slightly and less so among persons followed up for more than one year. Analysis by method of diagnosis showed no striking difference between the two methods. 
Table 2 Relative cancer risk by latency after start of cimetidine use (men)

\begin{tabular}{|c|c|c|c|c|c|c|c|c|c|c|}
\hline \multirow[b]{3}{*}{ Site } & \multicolumn{10}{|c|}{ Latency $(y r)$} \\
\hline & \multicolumn{2}{|l|}{$0-1$} & \multicolumn{2}{|l|}{$1-3$} & \multicolumn{2}{|l|}{$3-5$} & \multicolumn{2}{|l|}{$5+$} & \multicolumn{2}{|l|}{ Total } \\
\hline & Obs & $R R$ & Obs & $R R$ & Obs & $R R$ & Obs & $R R$ & Obs & $R R$ \\
\hline All sites & 169 & $1.9 \ddagger$ & 242 & $1.4 \ddagger$ & 165 & $1 \cdot 2^{*}$ & 37 & $1 \cdot 3$ & 613 & $1 \cdot 4$ \\
\hline Buccal cavity and pharnyx & 2 & $0 \cdot 8$ & 14 & $2 \cdot 7 \ddagger$ & 2 & 0.5 & 0 & - & 18 & 1.4 \\
\hline Digestive organs & 78 & $3 \cdot 5 \ddagger$ & 59 & $1 \cdot 3^{*}$ & 38 & $1 \cdot 1$ & 8 & $1 \cdot 1$ & 183 & $1 \cdot 7 \ddagger$ \\
\hline Oesophagus & 2 & $2 \cdot 2$ & 1 & $0 \cdot 6$ & 2 & $1 \cdot 4$ & 0) & - & 5 & $1 \cdot 2$ \\
\hline Stomach & 37 & $8 \cdot 2 \dagger$ & 14 & $1 \cdot 6$ & 7 & 0.9 & 3 & $2 \cdot 0$ & 61 & $2 \cdot 8+$ \\
\hline Small intestine & 2 & $8 \cdot 1^{*}$ & 1 & $2 \cdot 0$ & 1 & $2 \cdot 6$ & () & - & 4 & $3 \cdot 3^{*}$ \\
\hline Colon & 12 & $1.9 *$ & 21 & $1.7 *$ & 10 & $1 \cdot 0$ & 2 & $1 \cdot 0$ & 45 & $1 \cdot 5^{*}$ \\
\hline Rectum & 3 & $0 \cdot 6$ & 8 & $0 \cdot 8$ & 7 & 0.9 & 1 & $0 \cdot 6$ & 19 & 0.8 \\
\hline Liver & 2 & 1.9 & 4 & 1.9 & 1 & $0 \cdot 6$ & 0 & - & 7 & $1 \cdot 4$ \\
\hline Gall bladder & 2 & $3 \cdot 2$ & 1 & $0 \cdot 8$ & 1 & $1 \cdot 0$ & 0 & - & 4 & $1 \cdot 3$ \\
\hline Pancreas & 15 & $5 \cdot 2 \ddagger$ & 9 & $1 \cdot 6$ & 7 & $1 \cdot 6$ & 2 & $2 \cdot 1$ & 33 & $2 \cdot 3 \ddagger$ \\
\hline Respiratory system & 29 & $1 \cdot 4^{*}$ & 62 & $1 \cdot 5 \ddagger$ & 49 & $1.5 \dagger$ & 12 & $1 \cdot 8^{*}$ & 152 & $1.5 \div$ \\
\hline Male genital organs & 19 & $1 \cdot 8^{*}$ & 19 & 0.9 & 18 & $1 \cdot 1$ & 5 & $1 \cdot 4$ & 61 & $1 \cdot 2$ \\
\hline Urinary system & 12 & $1 \cdot 1$ & 32 & $1.5^{*}$ & 12 & $0 \cdot 7$ & 6 & $1 \cdot 7$ & 62 & $1 \cdot 2$ \\
\hline Lymphatic and hæmatopoetic tissue & 12 & $2 \cdot 3 \dagger$ & 11 & $1 \cdot 1$ & 11 & $1 \cdot 4$ & 2 & $1 \cdot 2$ & 36 & $1 \cdot 4^{*}$ \\
\hline
\end{tabular}

${ }^{*} \mathrm{p}<0 \cdot 05 ; \dagger \mathrm{p}<0 \cdot 01 ; \ddagger \mathrm{p}<0 \cdot(0) 1$ (one sided).

\section{Discussion}

This population based study showed a marked excess risk for gastric cancer and cancer of the small intestine in the first year of follow up of subjects prescribed cimetidine as treatment for gastric ulcer. We consider it highly probable that these tumours had initially been misdiagnosed as ulcers, as the initial symptoms of gastric cancer may resemble those of gastric ulcer.
Our findings indicate that a malignant component of gastric ulcer is difficult to diagnose, because the excess risk was of the same order of magnitude whether the diagnostic method used was endoscopy or $x$-ray. No information is available on the frequency of biopsies and histologic examination in the present material, and therefore it cannot be ruled out that endoscopy performed by an expert and with appropriate biopsies and histology may be superior to $x$-ray. In the present group of patients who were

Table 3 Relative cancer risk by latency after start of cimetidine use (women)

\begin{tabular}{|c|c|c|c|c|c|c|c|c|c|c|}
\hline \multirow[b]{3}{*}{ Site } & \multicolumn{10}{|c|}{ Latency $(y r)$} \\
\hline & \multicolumn{2}{|l|}{$0-1$} & \multicolumn{2}{|l|}{$1-3$} & \multicolumn{2}{|l|}{$3-5$} & \multicolumn{2}{|l|}{$5+$} & \multicolumn{2}{|c|}{ Total } \\
\hline & Obs & $R R$ & Obs & $R R$ & Obs & $R R$ & Obs & $R R$ & Obs & $R R$ \\
\hline All sites & 83 & $1 \cdot 7 \ddagger$ & 153 & $1 \cdot 6 \ddagger$ & 103 & $1 \cdot 4 \ddagger$ & 20 & $1 \cdot 4$ & 359 & $1 \cdot 5 \ddagger$ \\
\hline Buccal cavity and pharnyx & 0 & - & 4 & $3 \cdot 1^{*}$ & 1 & $1 \cdot 0$ & 0 & - & 5 & $1 \cdot 6$ \\
\hline Digestive organs & 49 & $4 \cdot 1 \ddagger$ & 50 & $2 \cdot 1 \ddagger$ & 31 & $1.7 \dagger$ & 9 & $2 \cdot 6$ & 139 & $2 \cdot 4 \ddagger$ \\
\hline Oesophagus & 0 & - & 1 & 1.8 & 0 & - & 0 & - & 1 & $0 \cdot 8$ \\
\hline Stomach & 20 & $12 \cdot 8 \ddagger$ & 13 & $4 \cdot 0 \ddagger$ & 9 & $3 \cdot 6 \ddagger$ & 2 & $4 \cdot 3$ & 44 & $5 \cdot 7 \ddagger$ \\
\hline Small intestine & 2 & $14.8 \dagger$ & 2 & $7 \cdot 3^{*}$ & 1 & $4 \cdot 8$ & 0 & - & 5 & $7 \cdot 6 \ddagger$ \\
\hline Colon & 11 & $2.5 \dagger$ & 17 & $1.9 *$ & 11 & $1 \cdot 6$ & 3 & $2 \cdot 3$ & 42 & $1.9 \ddagger$ \\
\hline Rectum & 3 & 1.4 & 7 & $1 \cdot 6$ & 5 & 1.5 & 0 & - & 15 & 1.4 \\
\hline Liver & 2 & $4 \cdot 6$ & 2 & $2 \cdot 2$ & 0 & - & 1 & $7 \cdot 7$ & 5 & $2 \cdot 3$ \\
\hline Gall bladder & 3 & $4 \cdot 1^{*}$ & 1 & 0.7 & 1 & $0 \cdot 9$ & 1 & $4 \cdot 6$ & 6 & $1 \cdot 7$ \\
\hline Pancreas & 6 & $3 \cdot 7 \dagger$ & 4 & $1 \cdot 2$ & 3 & $1 \cdot 2$ & 2 & $4 \cdot 2$ & 15 & $1.9 *$ \\
\hline Respiratory system & 5 & 1.4 & 21 & $3 \cdot 0 \ddagger$ & 11 & $2 \cdot 1^{*}$ & 1 & $1 \cdot 0$ & 38 & $2 \cdot 2 \ddagger$ \\
\hline Breast & 4 & 0.4 & 23 & $1 \cdot 1$ & 15 & $1 \cdot 0$ & 1 & $0 \cdot 3$ & 43 & 0.9 \\
\hline Female genital organs & 7 & 0.8 & 20 & $1 \cdot 2$ & 10 & $0 \cdot 8$ & 1 & $0 \cdot 4$ & 38 & 0.9 \\
\hline Urinary system & 3 & $1 \cdot 2$ & 9 & $1 \cdot 8$ & 8 & $2 \cdot 0^{*}$ & 0 & - & 20 & $1 \cdot 6^{*}$ \\
\hline Lymphatic and hæmatopoetic tissue & 10 & $4 \cdot 5 \ddagger$ & 2 & $0 \cdot 4$ & 5 & 1.5 & 2 & $3 \cdot 1$ & 19 & $1 \cdot 8^{*}$ \\
\hline
\end{tabular}

${ }^{*} \mathrm{p}<0 \cdot 05: \dagger \mathrm{p}<0 \cdot 01 ; \neq \mathrm{p}<0 \cdot 001$ (one sided). 
Table 4 Relative risk for gastric cancer by diagnosis and by method of diagnosis: men and women combined

\begin{tabular}{|c|c|c|c|c|c|c|c|c|c|c|}
\hline \multirow[b]{3}{*}{ Diagnosis/method of diagnoses } & \multicolumn{10}{|c|}{ Latency $(y r)$} \\
\hline & \multicolumn{2}{|l|}{$0-1$} & \multicolumn{2}{|l|}{$1-3$} & \multicolumn{2}{|l|}{$3-5$} & \multicolumn{2}{|l|}{$5+$} & \multicolumn{2}{|c|}{ Total } \\
\hline & Obs & $R R$ & Obs & $R R$ & Obs & $R R$ & Obs & $R R$ & Obs & $R R$ \\
\hline Duodenal ulcer & 7 & $2 \cdot 2^{*}$ & 7 & $1 \cdot 1$ & 5 & $1 \cdot 0$ & 2 & $1 \cdot 8$ & 21 & $1 \cdot 3$ \\
\hline Gastric ulcer & 45 & $19 \cdot 3 \ddagger$ & 16 & $3 \cdot 5 \ddagger$ & 10 & $2.9+$ & 3 & $4 \cdot 8^{*}$ & 74 & $6 \cdot 7$ 末 \\
\hline Other diagnosis & 5 & $8 \cdot 5$ & 4 & $3 \cdot 3^{*}$ & 1 & $1 \cdot 1$ & 0 & - & 10 & 3.54 \\
\hline Endoscopy & 30 & $12 \cdot 6 \ddagger$ & 7 & 1.5 & 6 & 1.7 & 3 & $5 \cdot()^{*}$ & 46 & $4 \cdot 1 末$ \\
\hline$X$-ray & 19 & $7 \cdot 3 \ddagger$ & 16 & $3 \cdot() \ddagger$ & 5 & 0.9 & 2 & $2 \cdot 2$ & 42 & $3 \cdot 1 \%$ \\
\hline Not stated & 8 & $7 \cdot 6 \ddagger$ & 4 & 1.9 & 5 & $3 \cdot 1^{*}$ & () & - & 17 & $3 \cdot 3 t$ \\
\hline
\end{tabular}

${ }^{*} \mathrm{p}<0 \cdot 05 ; \uparrow \mathrm{p}<0 \cdot 01 ; \neq \mathrm{p}<0 \cdot(0) 1$ (one sided).

routinely examined between 1977 and 1981, however, $x$-ray examination stands out as equivalent to endoscopy.

It is not possible from our material to evaluate the extent to which a correct diagnosis of cancer may have been delayed by administration of cimetidine. The proportion of localised stomach cancers, however, was higher among the cases observed in the cohort $(40 \%)$ than among all cases of gastric cancer reported to the Danish Cancer Registry in the period 1978-84 (25\%) and was consistent over all age groups. Thus, in comparison with other gastric cancer patients, those treated with cimetidine would appear to have a comparable or better prognosis.

The potential longterm effect of cimetidine on gastric cancer risk cannot be evaluated because of the short period of follow up. The persistently increased risk was seen only in patients with gastric ulcer, which is known to develop occasionally into malignant lesions.

The excess risk for cancers of lymphatic and haematopoietic system is largely attributable to an increased risk for non-Hodgkin's lymphomas. Of a total of 25 such tumours, 15 were reported to the Danish Cancer Registry as lymphomas in the stomach (12 cases) or small intestine (three cases), whereas only $8 \%$ of all non-Hodgkin's lymphomas were reported to the Danish Cancer Registry in 1978-84 arose in those organs. Thus, lymphomas in the stomach and small intestine may also produce symptoms that resemble those of an ulcer. Increased risks for cancers at other sites in the gastrointestinal tract (colon, liver, gall bladder, pancreas) during the first year of follow up indicate similarly that the gastrointestinal discomfort caused by these conditions may have been mistaken for a gastric ulcer.

The finding of an increased risk for cancer of the respiratory system was not surprising, as tobacco smoking is casually related to ulcer and lung cancer. ${ }^{1 \mathrm{x}}$ In line with this, the increased risk was spread evenly over the period of follow up. The increased risk of cancer of the urinary system seen may also be attributable to tobacco smoking.

Colin-Jones et al ${ }^{19}$ evaluated the incidence of gastric cancer in the first year after start of cimetidine use in about 10000 British users, and found an increased incidence compared with a control group. Analysis of cause of death ${ }^{21}$ showed a significant excess of gastric cancer, lung cancer, and cancers of the lymphatic and haematopoetic system in the first year of follow up. Four years after start of use of cimetidine, significantly increased risk of cancer was still maintained (relative risk $=1.4 ; 14.6$ excess deaths), but this excess was only attributable to increased risk of gastric cancer (relative risk $=2 \cdot 3 ; 4 \cdot 5$ excess deaths) and lung cancer (relative risk $=1 \cdot 8 ; 9 \cdot 5$ excess deaths). ${ }^{21}$

The excess risk of gastric cancer in the British material decreases rapidly with time after start of cimetidine use. In the first year, the relative risk is 12.9 but decrease hereafter to 3.4 in the second year and to about 2.0 in the fifth and fourth years. The results of the Danish and the British studies are thus in very good agreement, and our interpretation of the Danish data corresponds with the evaluation of the British data by Colin-Jones et al.

The data used here were not collected specifically for the purpose of evaluating morbidity among users of cimetidine, and they may not include those Danish citizens who were prescribed cimetidine in the period September 1977 to July 1981 who may have paid the full cost of the treatment themselves. This could introduce a bias as gastric cancer incidence is highest among persons of low socioeconomic status. When reimbursement for the drug was introduced as part of the National Health Service insurance scheme, however, little change was seen in the total amount of reimbursement. ${ }^{15}$ We assume, therefore, that the population of cimetidine users in the period September 1977 to July 1981 is well covered in this study.

We do not know, however, the extent to which the 
enrolled individuals continued to use the drug. Lack of this information will represent a problem when we evaluate the longterm effects of cimetidine, but it is of limited importance in the present context where we are concerned with cancer morbidity in the years immediately after the start of use of the drug.

In the absence of a proper control group, which would ideally have been a comparable group of untreated ulcer patients, we had to rely on national incidence rates to calculate expected numbers. The strong pattern with respect to latency seen for the excess risks for cancers of the digestive organs and of lymphatic and haematopoietic tissues, however, excludes the possibility that these effects could be the results of a selection bias.

In conclusion, a gastric ulcer patient who is prescribed cimetidine faces a 20 -fold increased risk for gastric cancer within the following year, irrespective of whether the ulcer was diagnosed by endoscopy or $x$-ray. While our findings indicate the need for improved precision in diagnostics, the population based nature of our study can be used to put the observed increase in risk into perspective. A total of 3900 cases of gastric cancer occurred in the Danish population during the period September 1977 to July 1981. In the present material of cimetidine users, about $3 \%$ of these appear. This indicates that, in absolute terms, only a few per cent of the incident cases of gastric cancer were in fact misdiagnosed and treated as gastric ulcers. In view of the relief provided to many ulcer patients by cimetidine, this figure may be considered to be acceptable.

Whether the hypoacidic conditions produced in the stomach by cimetidine and other antisecretory drugs might lead to an increased risk of cancer can be resolved only after another 15 years of follow up of this cohort.

We are grateful to Katja Boll who assisted with data processing, and to Jette Andersen and Marianne Lorentzen for preparing successive drafts of the manuscript.

\section{References}

1 Taylor RH, Menzies-Gow N, Lovell D, La Brooy SJ, Misiewicz JJ. Misleading response of malignant gastric ulcers to cimetidine. Lancet 1978; i: 686-8.

2 Elder JB, Ganguli PC, Gillespie IE. Cimetidine and gastric cancer. Lancet 1979; i: 1005-6.
3 Hawker PC, Muscroft TJ, Keighley MRB. Gastric cancer after cimetidine in patient with two negative pretreatment biopsies. Lancet 1980; i: 709-10.

4 Mosbech J, Videbæk A. Mortality from the risk of gastric carcinoma among patients with pernicious ancmia. Br Med J 1950; ii: 390-4.

5 Berkson J, Comfort MW, Butt HR. Occurrence of gastric cancer in persons with achlorhydria and with pernicious anemia. Mayo Clin Proc 1956; 31: 583-96.

6 Viste A. Bjørnestad E. Ophcim P, et al. Risk of carcinoma following gastric operations for benign disease. Lancet 1986; ii: 502-5.

7 Caygill CPJ. Hill MJ. Hall CN, Kirkham JS, Northfield TC. Increased risk of cancer at multiple sites after gastric surgery for peptic ulcer. Gut 1987; 28: 924-8.

8 Lundegårdh $\mathrm{G}$, Adami $\mathrm{H}-\mathrm{O}$, Helmick $\mathrm{C}$, Zack $\mathrm{M}$, Meirik $O$. Stomach cancer after partial gastrectomy for benign ulcer disease. $N$ Engl J Med 1988; 4: 195-200.

9 Toftgaard C. Gastric cancer after peptic ulcer surgery. A historic prospective cohort investigation. Ann Surg 1989: 210: 159-64.

10 Correa P. A human model of gastric carcinogenesis. Cancer Res 1988; 48: 3554-60.

11 Wormsley KG. Assessing the safety of drugs for the long-term treatment of peptic ulcers. Gut 1984; 25: 1416-23.

12 Langman MJS. Antisecretory drugs and gastric cancer. Br Med J 1985: 290: 1850-2.

13 Reed PI, Smith PLR, Haines K. House FR, Walters CL. Effect of cimetidine on gastric juice $\mathrm{N}$-nitrosamine concentration. Lancet 1981; ii: 553-6.

14 Reed PI, Smith PLR, Haines K. House FR, Walters CL. Gastric juice $\mathrm{N}$-nitrosamines in health and gastroduodenal disease. Lancet 1981; ii: 550-2.

15 Schmidt K, Mosbech J, Wors $\emptyset \mathrm{c}$ E. Cimetidine utilization in Denmark 1977-1981. Scand J Soc Med 1986; 14: 7-14.

16 Cancer Incidence in Denmark 1985. Danish Cancer Society, Danish Cancer Registry. Copenhagen: 1988.

17 Coleman M. Douglas A, Hermon C, Peto J. Cohort study analysis with a Fortran computer program. Int J Epidemiol 1986; 15: 134-7.

18 Smoking and health. Public Health Service, Publication no 1103 . Washington DC: 1964.

19 Colin-Jones DG, Langman MJS, Lawson DH, Vessey MP. Cimetidine and gastric cancer: preliminary report from post-marketing surveillance study. $\mathrm{Br}$ Med $J$ 1982; 285: 1311-3.

20 Colin-Jones DG. Langman MJS, Lawson DH, Vessey MP. Postmarketing surveillance of the safety of cimetidine: 12 month mortality report. $\mathrm{Br}$ Med J 1983; 286: 1713-6.

21 Colin-Jones DG, Langman MJS, Lawson DH, Vessey MP. Postmarketing surveillance of the safety of cimetidine: mortality during second, third, and fourth years of follow up. Br Med J 1985; 291: 1084-8. 